\title{
Heat Transfer and Fluid Flow in Naturally Ventilated Greenhouses
}

\author{
Mohamed Elashmawy \\ Dept. of Mechanical engineering \\ College of Engineering of Hail \\ Hail City, Saudi Arabia \\ $\&$
}

Engineering Science Department, Faculty of Petroleum and Mining Engineering, Suez

University, Suez, Egypt

arafat_696@yahoo.com

\section{Isam Badawy}

Dept. of Industrial engineering

College of Engineering of Hail

Hail City, Saudi Arabia

isam149@gmail.com

\author{
Abdullah A. A. A. Al-Rashed \\ Dept. of Automotive and Marine \\ Engineering Technology \\ College of Technological Studies, The \\ Public Authority for Applied Education \\ and Training, \\ Kuwait \\ aaa.alrashed@yahoo.com
}

Lioua Kolsi

Dept. of Mechanical engineering College of Engineering of Hail

Hail City, Saudi Arabia

\&

Unité de recherche de Métrologie et des Systèmes Energétiques, ENIM, University of Monastir, Monastir, Tunisia lioua_enim@yahoo.fr

Shamas Shoukat Ali

Dept. of Civil engineering College of Engineering of Hail

Hail City, Saudi Arabia ss.ali@uoh.edu.sa

\begin{abstract}
In this paper, heat transfer and fluid flow in naturally ventilated greenhouses are studied numerically for tow configuration according to the number and positions of the opening. The equations governing the phenomenon are developed using the stream function-vorticity formalism and solved using the finite volume method. The aim of the study is to investigate how buoyancy forces influence airflow and temperature patterns inside the greenhouse. Rayleigh number is the main parameter which changes from $10^{3}$ to $10^{6}$ and Prandtl number is fixed at $\operatorname{Pr}=0.71$. Results are reported in terms of stream function, isotherms and average Nusselt number. It is found that the flow structure is sensitive to the value of Rayleigh number and the number of openings. Also, that using asymmetric opening positions improve the natural ventilation and facilitate the occurrence of buoyancy induced upward cross-airflow inside the greenhouse.
\end{abstract}

Keywords-natural ventilation; open greenhouse,; heat transfer; fluid flow

\section{INTRODUCTION}

Ventilation plays a key role in ensuring good climate in a greenhouse and shear effort is conducted to ascertain the ventilation quality as a function of relevant parameters. The most unfavorable condition for greenhouse cooling is due to low wind speed, and natural ventilation is predominantly driven by buoyancy forces. The literature review reveals that previous studies focused on two dimensional ventilation models analysis. However, less research was attributed on the three dimensional characteristics of flow and temperature distribution in the greenhouse. Furthermore, the extensive perception of the impact of asymmetric opening position and roof inclination on natural ventilation potential yet to be evaluated. For instance, the pioneer CFD work in [1], represented a 2D distribution of climate inside greenhouses. In [2], authors described the convective cells that appear inside a closed half-model scale mono-span greenhouse and showed that for low Rayleigh numbers and during a transient regime, a flow pattern that takes the form of two counter-rotative air loops is initiated, whereas for higher Rayleigh numbers in the permanent regime, this pattern is replaced by a single convective loop that takes up the whole volume. In [3], authors conducted 2D simulations of the convective and radiative transfers under night conditions. The researchers revealed that two counter-rotative cells developed inside the shelter and enhanced the homogenization of the temperature distribution. In [4], authors simulated two counter-rotative cells and probed that during the night, the warm air moved up from the ground along the central partition and reached the roof and moved don after cooling. In [5], authors anticipated the ventilation induced by thermal buoyancy in a greenhouse. The greenhouse was equipped with the openings located at the lower part of the roof, just above the gutter. Authors compared a configuration with just one opening with the case of double symmetric vents by combining an experimental and a numerical approach. For both cases, the airflow was characterized by a single loop with higher velocities along the walls and ground, while the air was almost at rest at the center of the greenhouse. But in the case of the symmetric vents, one of the two openings played a 
dominant role in the air exchanges with the outside environment, and thus resulting in the cooling of the greenhouse. In [6], a single span greenhouse equipped with roof and side openings was considered. For low wind velocities, the results reported that fresh air entered the greenhouse through the side openings, moved horizontally along the ground where air got warmed, and moved up at the center of the building towards the roof openings where air was eliminated. In [7], authors carried out a two-dimensional numerical study of the same greenhouse but included the heat transfer occurring between the ground and the air inside the greenhouse. The researcher figured out that at zero external wind velocity, the qualitatively and quantitatively of velocity and temperature fields are in line with [6]. The capacity of CFD was estimated in [8] to predict greenhouse ventilation performance in order to optimize building design. The authors conducted 2D steady simulations, neglecting buoyancy effects and considering the wind as the main driving force. The study was focused on four configurations of a plastic tunnel greenhouse: (1) side openings only (roll-up type) at the middle of the walls; (2) identical to 1, along with side vents located on the upper part of the wall; (3) identical to 1, coupled with pivoting door type openings; and (4) identical to 1, but with an opening in the middle of the roof. Since, the air exchanges per hour are twice as much for case 4 as for case 1, the investigator concluded that the configuration 4 was the most efficient, while configuration 1 turned out to be the least efficient. It was concluded that the velocity patterns inside the greenhouse and the air temperature difference between the inside and outside, in addition to the ventilation rate, must be considered in order to choose the best configuration. Moreover, in all of the narrated cases, the temperature distribution follows the airflow patterns with high air temperatures in the greenhouse corners. Similar flows were also observed in [9] in a single-span greenhouse with side wall and roof openings. The air renewal inside a multi-span pitched-roof greenhouse compartment was studied in [10] using tracer gas techniques. The aim of this study is to investigate buoyancy-driven natural ventilation inside greenhouse, for two configurations related to number and position of openings, using 2D numerical simulation based on FVM and stream function-vorticity formalism.

\section{GEOMETRY, MATHEMATICAL MODEL AND NUMERICAL METHOD}

The physical model is presented in Figure 1. The considered problem is two-dimensional buoyancy-driven natural ventilation inside greenhouses. Two cases are considered according to the number of openings. Tbottom of the greenhouse is considered at higher temperature $T_{h}$ and all other walls are at cold temperature $\mathrm{T}_{\mathrm{c}}$. The thermo-physical properties of the nanofluid are assumed to be constant except for the density variation in the buoyancy term, which is approximated by the Boussinesq model. The stream functionvorticity formulation is used to express the governing equations for the laminar and unsteady state natural convection.

Scaling length, velocity and time by $W, \alpha / W$ and $W^{2} / \alpha$, and defining dimensionless temperature as $T=\left(T^{\prime}-T^{\prime}{ }_{c}\right) /\left(T^{\prime}{ }_{h}-T^{\prime}{ }_{c}\right)$, the governing equations in dimensionless stream functionvorticity form are:

- Vorticity

$\left(\frac{\partial \omega}{\partial t}+u \frac{\partial \omega}{\partial x}+v \frac{\partial \omega}{\partial y}\right)=\operatorname{Pr}\left(\frac{\partial^{2} \omega}{\partial x^{2}}+\frac{\partial^{2} \omega}{\partial y^{2}}\right)+R a \operatorname{Pr} \cdot \frac{\partial T}{\partial x}$

- $\quad$ Energy

$$
\left(\frac{\partial T}{\partial t}+u \frac{\partial T}{\partial x}+v \frac{\partial T}{\partial y}\right)=\left(\frac{\partial^{2} T}{\partial x^{2}}+\frac{\partial^{2} T}{\partial y^{2}}\right)
$$

- Kinematics

$$
\omega=-\left(\frac{\partial^{2} \Psi}{\partial x^{2}}+\frac{\partial^{2} \Psi}{\partial y^{2}}\right)
$$

The foregoing dimensionless parameters are given as follows:

$$
\operatorname{Pr}=\frac{v_{f}}{\alpha_{f}} \text { and } R a=\frac{g \cdot \beta_{f} \cdot \Delta T \cdot W^{3}}{v_{f} \cdot \alpha_{f}}
$$

The associated initial and boundary conditions for the problem considered are:

$$
\begin{gathered}
\text { For } t \leq 0: \\
\omega=\Psi=\frac{\partial \Psi}{\partial x}=\frac{\partial \Psi}{\partial y}=T=0 \text { (everywhere) }
\end{gathered}
$$

For $t>0$ :

On the horizontal bottom wall: $\Psi=\frac{\partial \Psi}{\partial y}=0 ; T=1$

On all other walls: $\Psi=\frac{\partial \Psi}{\partial n}=T=0$

At open boundary:

$$
\frac{\partial \Psi}{\partial x}=0
$$

$$
T_{i n}=T c \quad \text { if } n \cdot V<0 \text { and }\left.\frac{\partial T}{\partial x}\right|_{\text {out }}=0 \text { if } n . V \geq 0
$$

Local Nusselt is given as follows:

$$
N u=\left.\frac{\partial T}{\partial y}\right|_{y=0}
$$

The average values of Nusselt number, on the hot wall is expressed by:

$$
N u_{a v}=\int_{0}^{W} N u \cdot d x
$$

The governing equations (1)-(3) were discretized using the control-volume-finite-difference described in [11]. The central difference scheme for treating convective terms and the fully implicit procedure to discretize the temporal derivatives are retained. The grid is uniform in both directions with additional nodes on boundaries. The resulting nonlinear algebraic equations are solved using the successive relaxation-iterating scheme. The equation of radiative transfer is solved by repeatedly sweeping. The governing equations are represented by a general differential equation as follows: 


$$
\delta_{\chi} \frac{\partial \chi}{\partial t}+\frac{\partial}{\partial x}\left[u \chi-\Gamma_{\chi} \frac{\partial \chi}{\partial x}\right]+\frac{\partial}{\partial y}\left[v \chi-\Gamma_{\chi} \frac{\partial \chi}{\partial y}\right]=S_{\chi}
$$

Where $\chi$ stands for either $\omega$ or $T$ with:

$$
\begin{gathered}
\delta_{\omega}=1, \Gamma_{\omega}=\operatorname{Pr}, S_{\omega}=R a \cdot \operatorname{Pr} \cdot \frac{\partial T}{\partial x} \\
\delta_{T}=1, \Gamma_{T}=1, S_{T}=0
\end{gathered}
$$

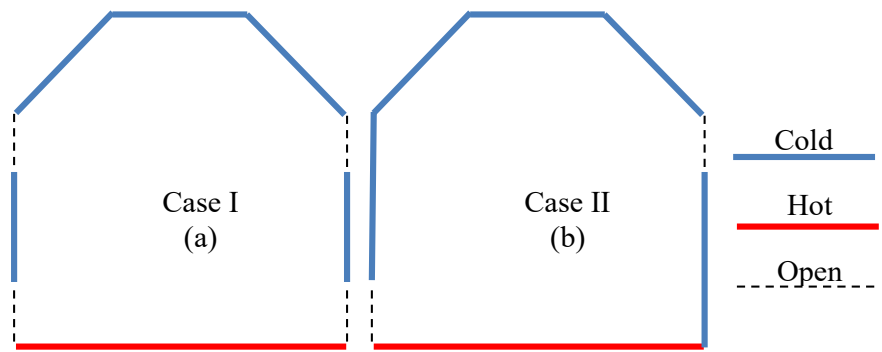

Fig. 1. Studied configurations: (a): case I, (b) case II.

\section{CONVERGENCE, GRID TESTING AND CODE VALIDATION}

An extensive mesh testing procedure was conducted to guarantee a grid independent solution. Five different mesh combinations were used for the case of $\mathrm{Ra}=10^{5}$ and $\mathrm{Pr}=0.7$. It is found that a grid size of $121 \times 121$ ensures an extremely grid independent solution. A time step of $10^{-4}$ is retained to carry out all numerical tests and all results are presented for a dimensionless time equal to 2 . The solution is considered acceptable when the following convergence criterion is satisfied for each step of time:

$$
\sum_{i}^{1,2,3} \frac{\max \left|\psi_{i}^{n}-\psi_{i}^{n-1}\right|}{\max \left|\psi_{i}^{n}\right|}+\max \left|T_{i}^{n}-T_{i}^{n-1}\right| \leq 10^{-5}
$$

A first validation (Figure 2) test was made by comparing the present code results for $\mathrm{Ra}=10^{5}$ and $\mathrm{Pr}=0.70$ against the numerical simulation of Khanafer et al. [12] in the case of differentially heated cavity. It is clear that the present code is in good agreement with other work reported in literature as shown in Figure 2.

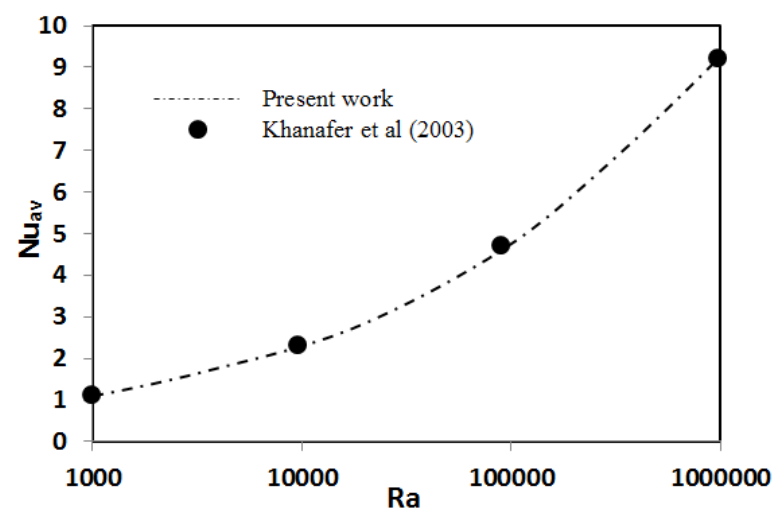

Fig. 2. Nusselt number versus Ra number; comparison with results of Khanafer et al [12].

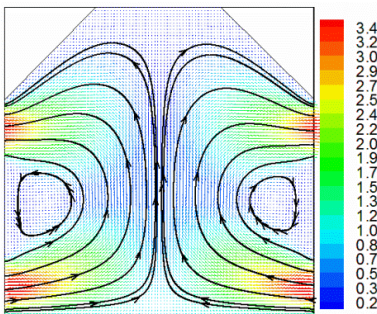

(a) $\mathrm{Ra}=10^{3}$
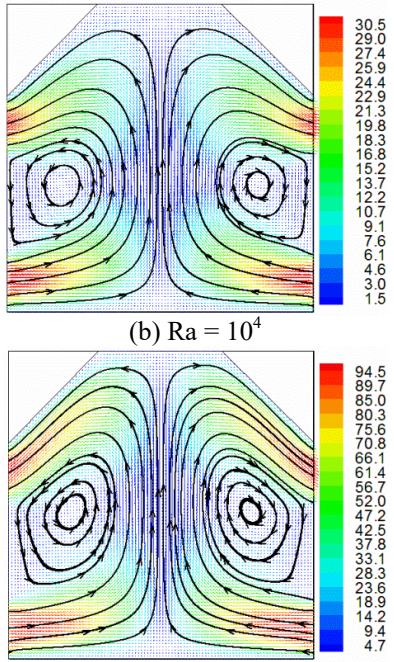

(c) $\mathrm{Ra}=10^{5}$

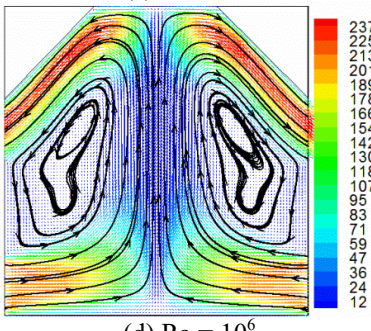

(d) $\mathrm{Ra}=10$ (b) $\mathrm{Ra}=10$

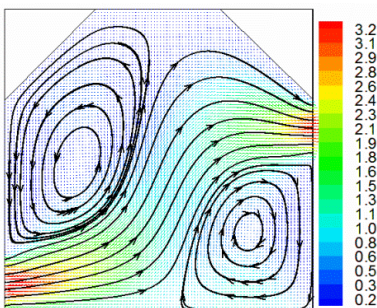

(a) $\mathrm{Ra}=10^{3}$

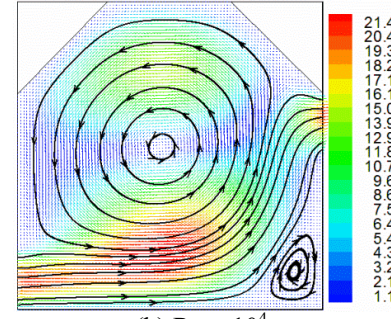

(b) $\mathrm{Ra}=10^{4}$

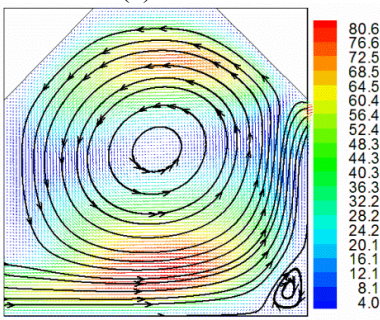

(c) $\mathrm{Ra}=10$

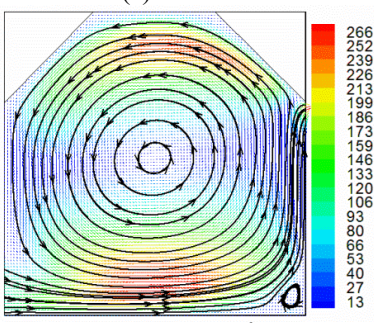

(d) $\mathrm{Ra}=10^{6}$
Fig. 3. Streamlines and velocity vectors profile for different Ra; case I (left) and case II (right)

\section{RESULTS AND DISCUSSION}

Figure 3 shows for the two cases the stream function and the velocity profile for different Rayleigh numbers. The fluid near the bottom wall is hotter than the fluid near the other walls. A density difference is formed due to this temperature difference. As a result, fluid rises from the heated portion and flows downwards to the cooled walls. For small values Rayleigh number the buoyancy effects are not very much sensitive and, therefore, the streamlines are almost circular. It is noticed that for all case the increase of $\mathrm{Ra}$ causes an intensification of the velocity at the opening and the higher region of the domain.

It is shown that for case I the flow structure is perfectly symmetric with tow circulation cells. The position of these cells becomes nearest to the center of the greenhouse by increasing Ra. For case II the flow is more complex due to the non-symmetrical boundary conditions. In fact the flow is characterized by one principal and one secondary circulation 
cells. The size the secondary cell reduces by increasing Ra due to the increase of the inflow air.

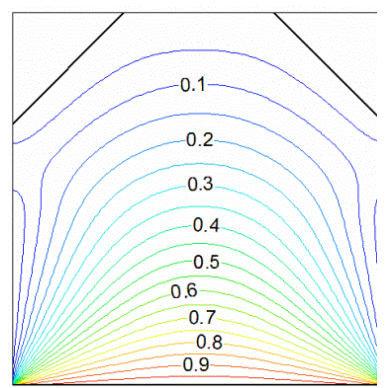

(a) $\mathrm{Ra}=10^{3}$

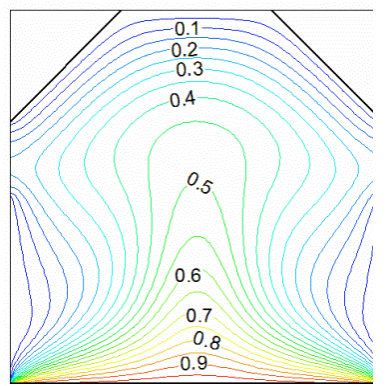

(b) $\mathrm{Ra}=10^{4}$

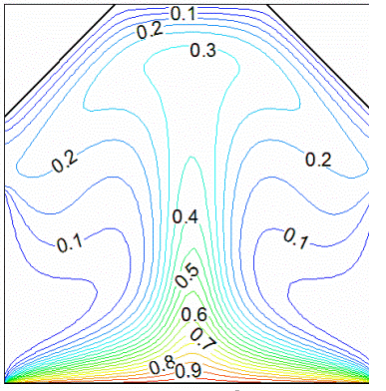

(c) $\mathrm{Ra}=10^{5}$

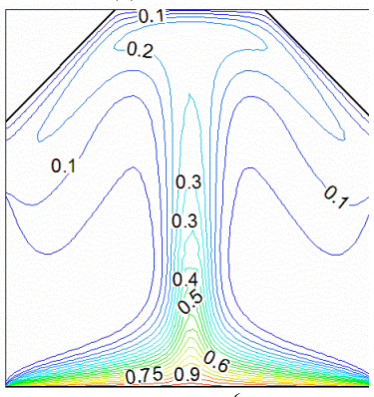

(d) $\mathrm{Ra}=10^{6}$

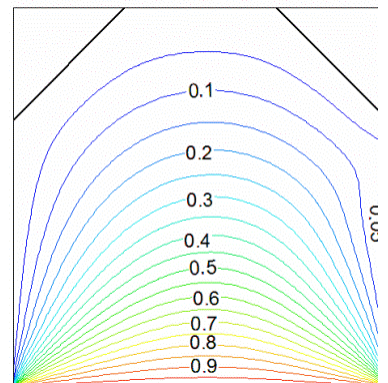

(a) $\mathrm{Ra}=10^{3}$

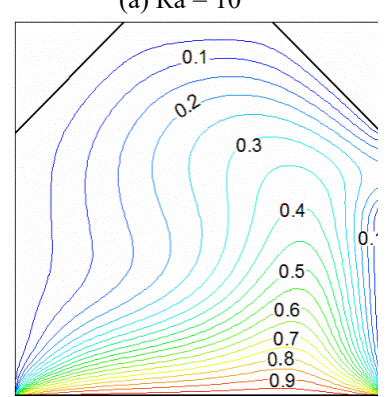

(b) $\mathrm{Ra}=10^{4}$

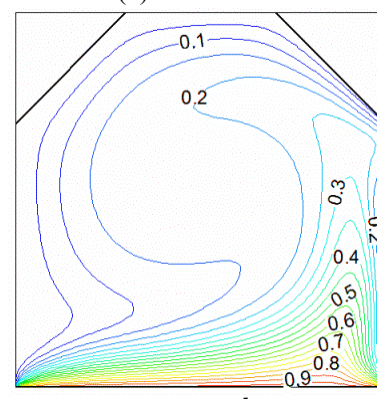

(c) $\mathrm{Ra}=10^{5}$

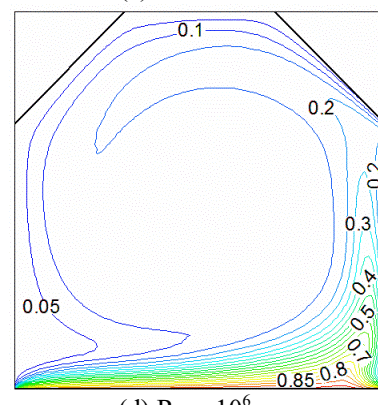

(d) $\mathrm{Ra}=10^{6}$
Fig. 4. Temperature field for different Ra: case I (left) and case II (right)

Figure 4 presents isotherms respectively for cases I and II. For low Rayleigh numbers the conduction mode of heat transfer is dominant to convection and isotherms present a quasi-vertical central stratification. Increasing $\mathrm{Ra}$ isotherms are altered due to enhancement of the flow especially near of the openings and the stratification becomes quasi-horizontal. It is noticed that as the flow structure the isotherms are perfectly symmetric for case I and a dissymmetry is encountered for case II especially for moderate $\mathrm{Ra}$ (104 and 105)

Figure 5 presents the variation of average Nusselt number versus $\mathrm{Ra}$ at the bottom wall for the two cases. The heat transfer for case II is clearly higher for about $22 \%$ due to the higher velocity near to this wall.

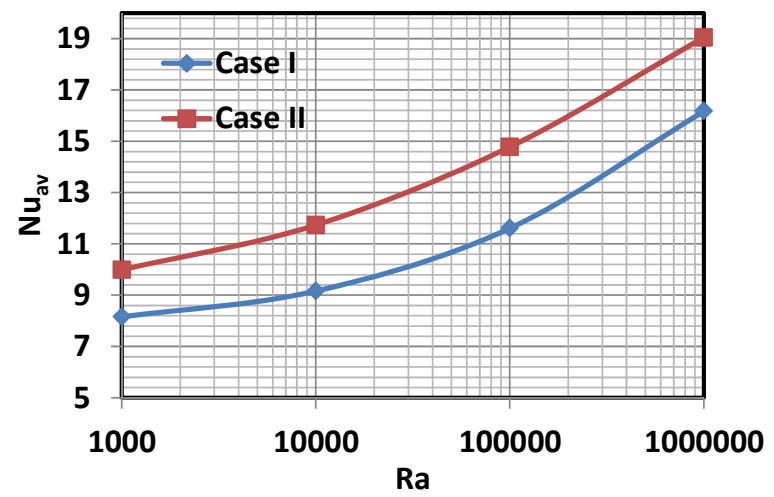

Fig. 5. Variation of average Nusselt number versus Ra for cases I and II

\section{CONCLUSION}

Study of heat transfer and flow inside greenhouses remains a problem of highly practical interest. A great deal of experimental and numerical studies have been made in an effort to understand the fundamental of the fluid flow involved with the problem and propose practical solutions. Through this research work, computational fluid dynamics (CFD) techniques have been used. It was found that in addition to Rayleigh number the opening location affect the flow structure and heat transfer.

\section{ACKNOWLEDGMENT}

The present work was undertaken within the research project (No: 0150282, 2015), funded by the Deanship of Scientific Research, at the University of Hail. This is gratefully acknowledged.

\section{NOMENCLATURE}

Be Bejan number

$\mathrm{Cp} \quad$ Specific heat at constant pressure $(\mathrm{J} / \mathrm{kg} . \mathrm{K})$

g Gravitational acceleration $\left(\mathrm{m} / \mathrm{s}^{2}\right)$

$\mathrm{k} \quad$ Thermal conductivity (W/m.K)

$\mathrm{n} \quad$ Unit vector normal to the wall

$\mathrm{Nu} \quad$ Local Nusselt number

Pr Prandtl number

Ra Rayleigh number

$\mathrm{t} \quad$ Dimensionless time $\left(t^{\prime} . \alpha / l^{2}\right)$

$\mathrm{T}$ Dimensionless temperature $\left[\left(T^{\prime}-T^{\prime}{ }_{c}\right) /\left(T^{\prime}{ }_{h}-T^{\prime}{ }_{c}\right)\right]$

$T_{c} \quad$ Dimensionless cold temperature $(\mathrm{K})$

$T_{h} \quad$ Dimensionless hot temperature $(\mathrm{K})$ 


$\begin{array}{ll}\mathrm{W} & \text { Enclosure width and height } \\ \mathrm{x}, \mathrm{y}, \mathrm{z} & \text { Dimensionless Cartesian coordinates } \\ \begin{array}{ll}\text { Greek symbols } \\ \alpha & \text { Thermal diffusivity }\left(\mathrm{m}^{2} / \mathrm{s}\right) \\ \beta & \text { Thermal expansion coefficient }(1 / \mathrm{K}) \\ \rho & \text { Density }\left(\mathrm{kg} / \mathrm{m}^{3}\right) \\ \mu & \text { Dynamic viscosity }(\mathrm{kg} . / \mathrm{m} . \mathrm{s}) \\ v & \text { Kinematic viscosity }\left(\mathrm{m}^{2} / \mathrm{s}\right) \\ \psi & \text { Dimensionless stream function } \\ \omega & \text { Dimensionless vorticity } \\ \Delta T & \text { Dimensionless temperature difference } \\ \text { Subscripts } & \\ \text { av } & \text { Average } \\ \mathrm{x}, \mathrm{y}, \mathrm{z} & \text { Cartesian coordinates }\end{array}\end{array}$

\section{REFERENCES}

[1] L. Okushima, S. Sase, M. Nara, "A support system for natural ventilation design of greenhouse based on computational aerodynamics", Acta Horticulturae, Vol. 248, pp. 129-136, 1989

[2] M. A. Lamrani, T. Boulard, J. C. Roy, A. Jaffrin, "Airflow and temperature patterns induced in a confined greenhouse", Journal of Agricultural Engineering Research, Vol. 78, pp. 75-88, 2001

[3] J. I. Montero, P. Munoz, A. Anton, N. Iglesias, "Computational fluid dynamic modelling of night-time energy fluxes in unheated greenhouses", Acta Horticulturae, Vol. 693, pp. 403-410, 2005

[4] P. E. Bournet, V. Winiarek, G. Chassériaux, "Coupled energy radiation balance in a closed partitioned glasshouse during night using computational fluid dynamics", International Symposium on Greenhouse Cooling: Methods, Technologies and Plant Response, Alméria, Spain, 24-27 April, 2006

[5] T. Boulard, R. Haxaire, M. A. Lamrani, J. C. Roy, A. Jaffrin, "Characterization and modelling of the air fluxes induced by natural ventilation in a greenhouse", Journal of Agricultural Engineering Research, Vol. 74, pp. 135-144, 1999.

[6] S. Sase, T. Takakura, M. Nara, "Wind tunnel testing on airflow and temperature distribution of a naturally ventilated greenhouse", Acta Horticulturae, Vol. 148, pp. 329-336, 1984

[7] A. Mistriotis, C. Arcidiacono, P. Picuno, G. P. A. Bot, G. ScarasciaMugnozza, "Computational analysis of ventilation in greenhouses at zero and low-windspeed", Agricultural and Forest Meteorology, Vol. 88, pp. 121-135, 1997

[8] T. Bartzanas, C. Kittas, "Optimisation of greenhouses ventilation performance with computational fluid dynamics", 2nd Southeastern Europe Fluent Users Group Meeting, Bucharest Romania, 2001

[9] J. I. Montero, G. R. Hunt, R. Kamaruddin, A. Anton, B. J. Bailey, "Effect of ventilator configuration on wind driven ventilation in a crop protection structure for the tropics", Journal of Agricultural Engineering Research, Vol. 80, No. 1, pp. 99-107, 2001

[10] C. Kittas, B. Draoui, T. Boulard, "Quantification of the ventilation of a greenhouse with a roof opening", Agricultural and Forest Meteorology, Vol. 77, No. 1, pp. 95-111, 1995

[11] S. V. Patankar, Numerical Heat Transfer and Fluid Flow, Hemisphere, McGraw Hill, New York. 1980.

[12] K. Khanafer, K. Vafai, M. Lightstone, "Buoyancy-driven heat transfer enhancement in a two-dimensional enclosure utilizing nanofluids", International Journal of Heat and Mass Transfer, Vol. 46, pp. 36393653,2003 